\title{
Water Economy via Oriented Root Elongation of Mediterranean Plants: Physiological Parameters
}

\author{
Chrysanthi Chimona, Sophia Rhizopoulou
}

\begin{abstract}
Plant species grown in the Mediterranean region have been selected for an experimental study regarding plant ability to endure harsh, abiotic conditions such as water deficiency. Young plants of Ceratonia siliqua L., Myrtus communis L., Nerium oleander L., Rosmarinus officinalis $\mathbf{L}$. and Pittosporum tobira (Thunb.) were placed in elongated plastic tubes and rhizotrons, which allow non-destructive observations of plant material, and were grown under controlled light and temperature conditions, with varying irrigation patterns in a growth chamber, for a 30-day period. Sugar, proline and chlorophyll content were measured in above and below ground tissues of the considered species, during the 30-day experimental period. The results show that Ceratonia siliqua, Myrtus communis and Nerium oleander are more capable of enduring drought conditions, in comparison to Rosmarinus officinalis L. and Pittosporum tobira (Thunb.). The results can be used for planning green urban landscapes with introduction of naturalistic planting, using plant species adapted to the scarcity of water during prolonged, ambient drought conditions.
\end{abstract}

Index Terms - Drought, Mediterranean, Roots, Urban landscape, Water stress

\section{INTRODUCTION}

The climate of the Mediterranean ecosystems is characterized by hot, arid summers and wet winters [1]. The common life forms in the Mediterranean region are evergreen trees and shrubs that tolerate the dry period [2-3]. Generally, Mediterranean-type ecosystems cover the majority of the territory of Greece [4]; however, urban landscape is affected by human activities and therefore consists of a variety of native, introduced and alien plant species, including many ornamental species.

Drought is a severe abiotic factor that causes stress to plants [5] and affects plant growth and distribution in wild and cultivated lands [6]. In arid and semiarid habitats, water availability, soil nutrient scarcity, elevated temperature and excess of solar radiation are the main constraints on plants' survival [7]. Under natural conditions, repeated, episodic drought events might be severe and durable, which affect plants' acclimation [8]. In the Mediterranean region, problems associated with water scarcity continuously enhance; therefore, initiatives towards solutions including

Chrysanthi Chimona, Department of Botany, Faculty of Biology National and Kapodistrian University of Athens, Athens, Greece

Sophia Rhizopoulou, Department of Botany, Faculty of Biology National and Kapodistrian University of Athens, Athens, Greece

The study is funded by IKY FELLOWSHIPS OF EXCELLENCE FOR POSTGRADUATE STUDIES IN GREECE - SIEMENS PROGRAM. water management are of high priority.

Plants' responses to drought stress tolerance include biochemical, molecular, morphological and physiological mechanisms [9-11]. When the natural conditions are stressful, the vegetative growth, life cycle and reproduction of plants may be inhibited [12]. The root system is very important for plants to overcome water stress; for example, plants living in arid and semi-arid environments achieve access to water regimes found in deep soil layers by elongating their roots [11], [13]. Although different root lengths exist among plant growth forms, there is plasticity in root response to habitat conditions, depending on the plants species [14]. Also, the soil characteristics affect the root development [15]. Deep roots are important not only for water uptake, but also for the rhizosphere and the soil micro-environment [16]. Plant species have developed different acclimation strategies of water uptake from either deep or shallow water horizons by balancing between (root) growth cost and access to water horizons in the soil [17].

In plants adapted to adverse conditions effective response mechanisms have been developed [6]. Such responses encompass the closure of stomata and the production of metabolites (sugars, amino acids, secondary metabolites etc.) that enable plants to maintain their functions under water scarcity [18-19]. Increased accumulation of compatible solutes -such as soluble sugars and proline-in plant tissues is a strategy of withholding water from dry environmental conditions [20]. Soluble substances are involved in turgor maintenance and membrane stabilization of plant tissues [21]. Accumulated osmolytes contribute to osmotic adjustment and ion homeostasis [22]; in addition, they can stabilize proteins and membrane structures [6], [23].

Proline is usually accumulated in plant tissues in response to water deficit. There are several studies that affirm the correlation of proline levels in plant tissues with water stress [24-27]. Drought regulates proline biosynthesis genes with induction of proline synthesis from glutamate [23]. In some plants there is developmental control of proline accumulation in different organs [28-29]. Also, proline may act as nitrogen storage in stressed plants that concomitantly slow their growth rate [30-31].

The cells' membranes are destabilized when exposed to prolonged water stress periods e.g. changes in sugar content may cause membrane dysfunction and subsequently cell death [32]. Also, during periods of water stress the chloroplasts' membranes destabilization can be avoided by the presence of sugars [12], [33]. Sugars contribute to the cells' osmotic adjustment by decreasing the osmotic potential 
and thus promoting the movement of water into the cells, in water deficient ecosystems [12]. The increase of soluble sugars concentration can be deployed as a metabolic signal in response to stress [31]. In fact, many Mediterranean species exhibit non-rapid growth rates [34]. Plant nutrient uptake and photosynthesis may be reduced and/or inhibited, during the dry period [10], [35]; also, chlorophyll content is affected by drought and can be used as physiological trait of plants' status [36-37].

The study and knowledge of roots' depth and functionality is important to understand water-energy-carbon exchange, plant productivity and plant acclimation to environmental conditions [14]. Techniques that enable researchers to study root functionality without intervention include tubes and rhizotrons. Rhizotrons can be considered modified human-induced forms that involve in situ root observation; these are non-destructive methods that allow periodical observations of the roots, sampling and visualization of their growth [17].

Ceratonia siliqua L. (carob tree), Myrtus communis L. (myrtle) and Nerium oleander L. (oleander) are evergreen species native to the Mediterranean region, Rosmarinus officinalis L. (rosemary) is an aromatic shrub, whereas Pittosporum tobira (Thunb.) (Japanese pittosporum) is a native species to the Far East that has been introduced to the Mediterranean region and is often encountered in urban spaces [34], [38].

The aim of the present study is to evaluate and understand different plant species' response to water stress by comparing physiological parameters.

\section{MATERIALS AND MethodS}

\section{A. Plant Material}

Young plants of Ceratonia siliqua L., Myrtus communis L., Nerium oleander L., Rosmarinus officinalis L. and Pittosporum tobira (Thunb.) were placed in plastic tubes (10 $\mathrm{cm}$ in diameter and $100 \mathrm{~cm}$ in length) and rhizotrons $(3 \mathrm{~cm}$ thick x $30 \mathrm{~cm}$ wide x $50 \mathrm{~cm}$ long) (Fig. 1). The plastic tubes

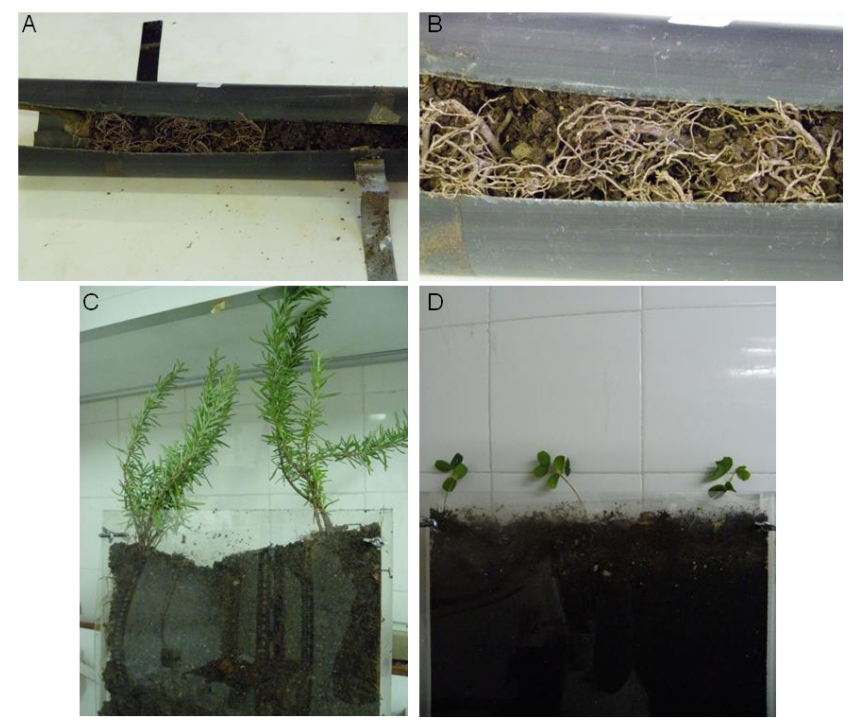

Fig. 1 Samples of the studied plants. N. oleander in plastic tubes (a, b), R. officinalis and C. siliqua in rhizotrons (c and d, respectively).

were treated as described by Sharp and Davies (1985) [39], i.e. they were cut along their length, while maintaining their volume and soil columns. This arrangement allows monitoring of root development and water status, as well as sampling of segments throughout the study [40]. In addition, the rhizotrons allow non-intervened observations of root growth. Tubes and rhizotrons with the studied species were kept in a growth chamber, at $25 \pm 1{ }^{\circ} \mathrm{C}, 50 \%$ relative humidity and $16 \mathrm{~h}$ photoperiod $\left(500 \mu \mathrm{mol} \mathrm{m} \mathrm{s}^{-2} \mathrm{PAR}\right)$. Plants inserted in the tubes and the rhizotrons remained under well watering conditions for a week. Then, they were exposed to environmental conditions simulating the Mediterranean summer, water deficit conditions. The tubes were carefully opened and samples of roots and shoots were collected at five-day intervals, during the experimental period. Tissue samples were oven-dried at $50{ }^{\circ} \mathrm{C}$ for $72 \mathrm{~h}$, weighted, and grounded for the subsequent analyses using a Thomas Wiley Model 4 Mill (Thomas Scientific, Swedesboro, NJ, USA).

\section{B. Chlorophyll}

The total chlorophyll (Chl) content was spectrophotometrically determined in leaf samples according to a modified acetone method [41]. Chlorophyll was extracted from $0.1 \mathrm{~g}$ dried and grinded samples, homogenized with $10 \mathrm{~mL}$ acetone $(80 \% \mathrm{v} / \mathrm{v})$ and filtered through Whatman \#2 filter paper to become fully transparent [42]. The chlorophyll content was measured in aliquots of the tissue extracts using a Novaspec II (Pharmacia Biotech, Cambridge, England) spectrophotometer; absorbance readings of five replicates have been used for the calculations. Chlorophyll content is expressed as $\mu \mathrm{g} \mathrm{g}^{-1}$ of dry weight of the tissue.

\section{Proline}

The concentration of proline was determined spectrophotometrically according to the method described by Bates et al. (1973) [43]. Dried tissue samples were crushed into fine powder and homogenized with aqueous sulphosalicylic acid $(20 \mathrm{~mL}, 3 \% \mathrm{w} / \mathrm{v})$, and the homogenate filtered through Whatman \# 2 filter paper. Two $\mathrm{mL}$ of the filtrate reacted with acid-ninhydrin solution $(2 \mathrm{~mL})$ and glacial acetic acid $(2 \mathrm{~mL})$ in triplicate test tubes, which were heated at $100{ }^{\circ} \mathrm{C}$ for $1 \mathrm{~h}$ in a water bath and the reaction terminated in an ice bath. After cooling, the reaction mixture was extracted with $4 \mathrm{~mL}$ toluene, homogenized in a vortex. The chromophore containing the toluene was aspirated from the aqueous phase and the absorbance at $520 \mathrm{~nm}$ was measured using toluene as a blank sample. Values of proline content are expressed as $\mu \mathrm{mol} \mathrm{g} \mathrm{g}^{-1}$ of dry weight; L-proline (Serva, Heidelberg, Germany) solutions were used for the standard curve.

\section{Soluble sugars}

The concentration of sugars was determined spectrophotometrically according to the sulfuric acid method described by Albalasmeh et al. (2013) [44]; dried and grinded tissues $(0.1 \mathrm{~g})$ were homogenized in $20 \mathrm{ml}$ of double distilled water. $1 \mathrm{~mL}$ of sample solution was mixed with $3 \mathrm{~mL}$ of sulfuric acid in a test tube and agitated for $30 \mathrm{~s}$. Then, the solution was cooled in ice for $2 \mathrm{~min}$ to bring it to room temperature. Finally, light absorption was read using UV-vis spectrophotometer at $315 \mathrm{~nm}$. The results are expressed as $\mathrm{mg} \mathrm{g}^{-1}$ of dry weight of the tissue. 


\section{E. Statistical analysis}

The results are presented in charts as mean values \pm Standard Error (S.E.). In order to determine the differences in ecophysiological response of the studied species during the experimental conditions, a one-way analysis of variance (ANOVA) was performed at $p \leq 0.05$ and the Tukey test was applied to compare the means. All statistical tests were performed using the SPSS statistical v. 23.0 (SPSS Inc., Chicago, IL, USA).

\section{RESUlTs AND DisCUSSION}

\section{A. Chlorophyll}

The measurements of leaf chlorophyll content are shown in Fig. 2. The chlorophyll content declined in the considered species during the water stress period. $C$. siliqua and $M$. communis present rather stable values, whereas in $R$. officinalis fluctuations have been observed during the experiment. By the end of the water stress treatment some $P$. tobira and $R$. officinalis plants exhibited yellow-colored leaves- i.e. a phenotypic result indicating loss of chlorophyll. Under severe water stress conditions pigment depletion might lead to cell membrane destruction [37]. Under natural conditions, $N$. oleander is capable of photosynthetic acclimation, providing a stable photosynthetic mechanism during the dry period [35]. In the current study, unwatered $N$. oleander plants showed decreased chlorophyll content; however, along with $C$. siliqua and $M$. communis, they showed smaller chlorophyll losses compared to $R$. officinalis and $P$. tobira.

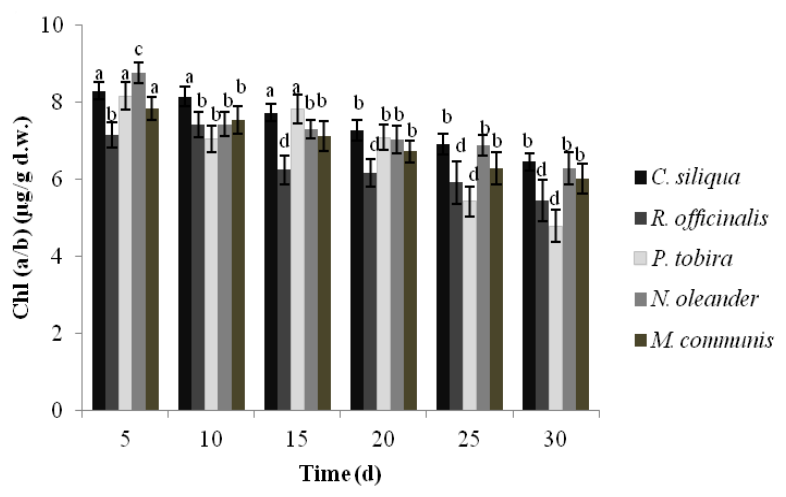

Fig. 2 Chlorophyll content. Values are means \pm SE. Significant differences $(p \leq 0.05)$ of mean values are marked using lowercase letters.

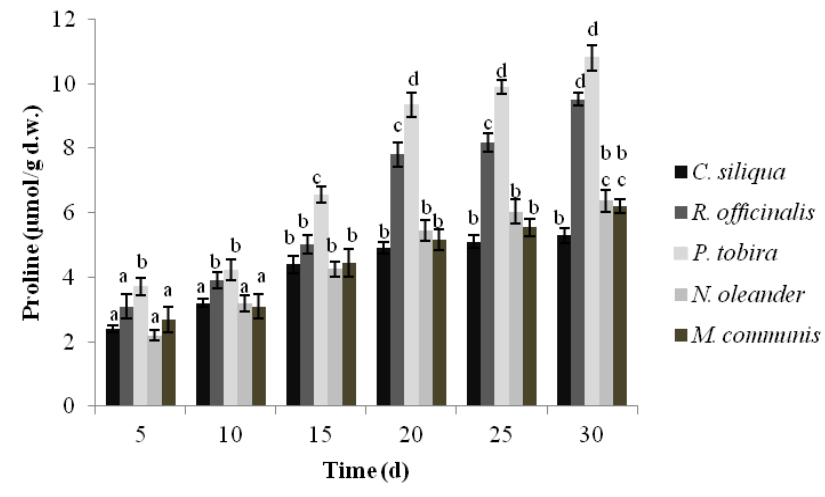

Fig. 3 Shoot total sugar content. Values are means \pm SE. Significant differences $(p \leq 0.05)$ of mean values are marked using lowercase letters.

\section{B. Proline}

The results of root proline content in the considered plant species are presented in Fig. 3. C. siliqua, M. communis and $N$. oleander show a stable increase in root proline content, whereas $P$. tobira and $R$. officinalis present a more abrupt increase in proline content after 15 days of treatment; by the end of the study (30 days), proline content was substantially increased in most of the considered species, especially $R$. officinalis and $P$. tobira. Proline content is useful as an indicator of drought stressed plants [25], [45-46] and it affects stress tolerance of plants in multiple ways [23]. The results indicate that $P$. tobira and $R$. officinalis undergo more stress than $C$. siliqua, M. communis and $N$. oleander.

\section{Soluble sugars}

Both shoot (Fig. 4) and root (Fig. 5) sugar content increases in the studied species during the water withholding treatment. Shoot measurements appear higher than those of the root samples; in considering both tissues, $P$. tobira shows the highest sugar content, followed by the shoots of $R$. officinalis and the roots of $M$. communis. Other studies have shown that the highest amounts of shoot soluble sugars were found in species with shallow root system [47]. Deep rooted plants like $C$. siliqua possess survival tactics under water-withholding conditions [48].

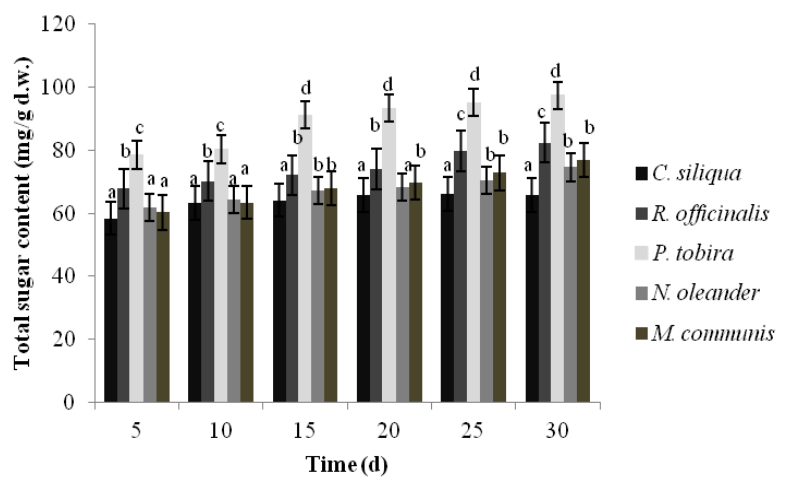

Fig. 4 Root total sugar content. Values are means \pm SE. Significant differences $(p \leq 0.05)$ of mean values are marked using lowercase letters. 


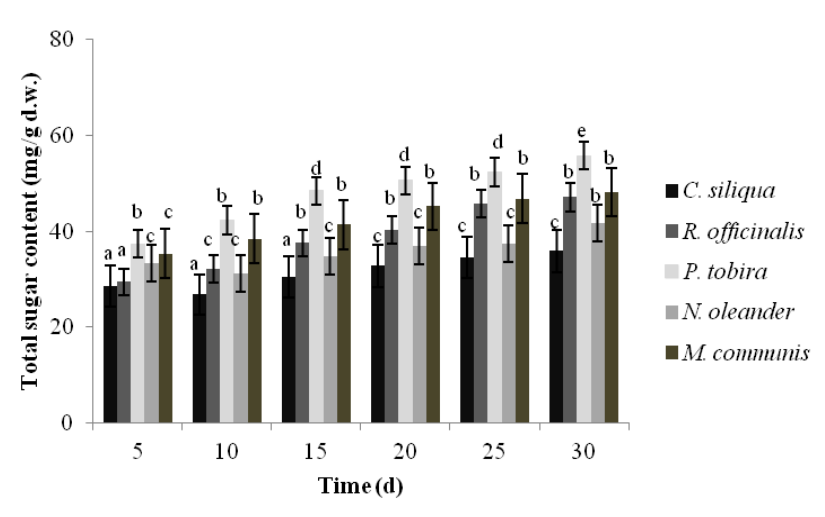

Fig. 5 Root proline content. Values are means \pm SE. Significant differences $(p \leq 0.05)$ of mean values are marked using lowercase letters.

\section{CONCLUSION}

Abiotic stress affects plant growth and productivity; plant metabolism is perturbed and the network needs to be reconfigured [19]. It is noteworthy to mention that tissues' water potential of plants placed in pots and exposed to controlled watering conditions, might change faster than those of plant exposed to the same conditions in the field [49]. Knowledge of plant species that use effective mechanisms to cope with water scarcity will help us to develop green urban landscapes irrigated with declining water consumption. Ecophysiological characteristics of native and cultivated plants that grow under the Mediterranean climatic conditions indicate resistance to drought stress [34], [50]. It seems likely that drought-tolerant species should be taken into consideration for planting areas with inadequate irrigation conditions.

\section{REFERENCES}

[1] H. Aschmann, "Distribution and peculiarity of Mediterranean ecosystems", in Mediterranean type ecosystems, F. di Casrti, H. A. Mooney, Eds. Springer Berlin Heidelberg, 1973, pp. 11-19.

[2] H. A. Mooney and E. L. Dunn, "Convergent evolution of Mediterranean- climate evergreen sclerophyll shrubs", Evolution, 24(2), 1970, pp. 292-303.

[3] S. Rhizopoulou and K. Mitrakos, "Water relations of evergreen sclerophylls. I. Seasonal changes in the water relations of eleven species from the same environment", Annals of Botany, 65(2), 1990 pp. $171-178$

[4] K. Georghiou and P. Delipetrou, "Patterns and traits of the endemic plants of Greece", Botanical Journal of the Linnean Society, 162(2), 2010, pp. 130-422.

[5] E. A. Bray, "Responses to abiotic stresses", in Biochemistry and Molecular Biology of Plants, 2nd ed., B. Buchanan, W. Gruissem and R. L. Jones, Eds. Wiley Blackwell, 2000, pp.1158-1203.

[6] O. Vicente, M. Al Hassan, and M. Boscaiu, "Contribution of osmolyte accumulation to abiotic stress tolerance in wild plants adapted to different stressful environments", in Osmolytes and Plants Acclimation to Changing Environment: Emerging Omics Technologies, N. Iqbal, R. Nazar and N. A. Khan, Eds. Springer India, 2016, pp. 13-25.

[7] F. Valladares, "Light heterogeneity and plants: from ecophysiology to species coexistence and biodiversity", in Progress in Botany, K. Esser, U. Lüttge, W. Beyschlag, F. Hellwig, Eds. Springer Berlin Heidelberg, 2003, pp. 439-471.

[8] P. E. Menezes-Silva, L. M. Sanglard, R. T. Ávila, L. E. Morais, S. C. Martins, P. Nobres, C. M. Patreze, M. A. Ferreira, W. A. Araújo, A. R. Fernie and F. M. DaMatta, "Photosynthetic and metabolic acclimation to repeated drought events play key roles in drought tolerance in coffee”, Journal of Experimental Botany, 68(15), 2017, pp. 4309-4322.
[9] J. B. Passioura, "Drought and drought tolerance", in Drought Tolerance in Higher Plants: Genetical, Physiological and Molecular Biological Analysis, E. Belhassen, Ed. Springer Netherlands, 1996, pp. $1-5$.

[10] P. Villar-Salvador, L. Ocaña, J. Peñuelas and I.Carrasco, "Effect of water stress conditioning on the water relations, root growth capacity, and the nitrogen and non-structural carbohydrate concentration of Pinus halepensis Mill. (Aleppo pine) seedlings". Annals of Forest Science, 56(6), 1999, pp. 459-465.

[11] D. Gui, F. Zeng, Z. Liu and B Zhang, "Root characteristics of Alhagi sparsifolia seedlings in response to water supplement in an arid region, northwestern China", Journal of Arid Land, 5(4), 2013, pp. 542-551.

[12] S. Mahajan and N. Tuteja, "Cold, salinity and drought stresses: an overview", Archives of Biochemistry and Biophysics, 444(2), 2005, pp. $139-158$.

[13] P. E. Villagra and J. B. Cavagnaro, "Water stress effects on the seedling growth of Prosopis argentina and Prosopis alpataco", Journal of Arid Environments, 64(3), 2006, pp. 390-400

[14] Y. Fan, G. Miguez-Macho, E. G. Jobbágy, R. B. Jackson and C. Otero-Casal, "Hydrologic regulation of plant rooting depth", PNAS, 2017, 201712381

[15] S. Rhizopoulou and G. Kapolas, "In situ study of deep roots of Capparis spinosa $\mathrm{L}$. during the dry season: Evidence from a natural "rhizotron" in the ancient catacombs of Milos Island (Greece)", Journal of Arid Environments, 119, 2015, pp. 27-30.

[16] A. G. Bengough, "Water dynamics of the root zone: rhizosphere biophysics and its control on soil hydrology", Vadose Zone Journal, 11(2), 2012, doi:10.2136/vzj2011.0111.

[17] J. L. Maeght, B. Rewald and A. Pierret, "How to study deep roots and why it matters", Frontiers in Plant Science, 4, 2013, doi: 10.3389/fpls.2013.00299.

[18] C. Chimona, A. Stamellou, A. Argiropoulos and S. Rhizopoulou, "Study of variegated and white flower petals of Capparis spinosa expanded at dusk in arid landscapes”, Journal of Arid Land, 4(2), 2012 pp. 171-179.

[19] T. Obata and A. R. Fernie, "The use of metabolomics to dissect plant responses to abiotic stresses", Cellular and Molecular Life Sciences, 69(19), 2012, pp. 3225-3243.

[20] P. H. Yancey, M. E. Clark, S. C. Hand, R. D. Bowlu and G. N Somero, "Living with water stress: evolution of osmolyte systems", Science, 217(4566), 1982, pp. 1214-1222.

[21] F. A. Hoekstra, E. A. Golovina and J. Buitink, "Mechanisms of plant desiccation tolerance", Trends in Plant Science, 6(9), 2001, pp. 431-438.

[22] J. C. Cushman, "Osmoregulation in plants: implications for agriculture", American Zoologist, 41(4), 2001, pp. 758-769.

[23] L. Szabados and A. Savouré, "Proline: a multifunctional amino acid", Trends in Plant Science, 15(2), 2009, pp. 89-97.

[24] S. Sivaramakrishnan, V. Z. Patell, D. J. Flower and J. M. Peacock, "Proline accumulation and nitrate reductase activity in contrasting sorghum lines during mid- season drought stress", Physiologia Plantarum, 74(3), 1988, pp. 418-426.

[25] S. Rhizopoulou, S. T. Diamantoglou and L. Passiakou, "Free proline accumulation in leaves, stems and roots of four Mediterranean native phrygana species", Acta Oecologica, 11(4), 1990, pp. 585-593.

[26] P. D. Hare, W. A. Cress and J. Van Staden, "Proline synthesis and degradation: a model system for elucidating stress-related signal transduction", Journal of Experimental Botany, 50(333), 1999, pp. 413-434.

[27] F. Ain-Lhout, M. Zunzunegui, M. D. Barradas, R. Tirado, A. Clavijo and F. G. Novo, "Comparison of proline accumulation in two Mediterranean shrubs subjected to natural and experimental water deficit", Plant and Soil, 230(2), 2001, pp. 175-83.

[28] S. Diamantoglou and S. Rhizopoulou, "Free proline accumulation in sapwood, bark and leaves of three evergreen sclerophylls and a comparison with an evergreen conifer", Journal of Plant Physiology, 140(3), 1992, pp. 361-365.

[29] Z. Zegaoui, S. Planchais, C. Cabassa, R. Djebbar, O. A. Belbachir and P. Carol, "Variation in relative water content, proline accumulation and stress gene expression in two cowpea landraces under drought", Journal of Plant Physiology, 218, 2017, pp. 26-34.

[30] H. J. Bohnert and R. G. Jensen, "Strategies for engineering water-stress tolerance in plants", Trends in Biotechnology, 14(3), 1996, pp. 89-97.

[31] M. M. Chaves, J. P. Maroco and J. S. Pereira, "Understanding plant responses to drought - from genes to the whole plant", Functional Plant Biology, 30(3), 2003, pp. 239-264.

[32] M. Bajji, J. M. Kinet and S. Lutts, "The use of the electrolyte leakage method for assessing cell membrane stability as a water stress tolerance 
test in durum wheat", Plant Growth Regulation, 36(1), 2002, pp. $61-70$.

[33] K. A. Santarius, "The protective effect of sugars on chloroplast membranes during temperature and water stress and its relationship to frost, desiccation and heat resistance", Planta, 113(2), 1973, pp. $105-114$

[34] M. S. Meletiou-Christou and S. Rhizopoulou, "Leaf functional traits of four evergreen species growing in Mediterranean environmental conditions", Acta Physiologiae Plantarum, 39(1), 2017, 34 doi:10.1007/s11738-016-2330-4.

[35] M. S. Meletiou-Christou and S. Rhizopoulou, "Constraints of photosynthetic performance and water status of four evergreen species co-occurring under field conditions", Botanical Studies, 53(3), 2012, pp, 325-334

[36] L. Yanqiong, L. Xingliang, Z. Shaowei, C. Hong, Y. Yongjie, M. Changlong and L. Jun, "Drought-resistant physiological characteristics of four shrub species in arid valley of Minjiang River, China", Acta Ecologica Sinica, 27(3), 2007, pp. 870-877.

[37] C. R. Guadagno, B. E. Ewers, H. N. Speckman, T. L. Aston, B. J. Huhn, S. B. DeVore, J. T. Ladwig, R. N. Strawn and C. Weinig, "Dead or alive? Using membrane failure and chlorophyll fluorescence to predict mortality from drought", Plant Physiology, 2017, doi:10.1104/pp.16.00581.

[38] S. Munné-Bosch and L. Alegre, "Changes in carotenoids, tocopherols and diterpenes during drought and recovery, and the biological significance of chlorophyll loss in Rosmarinus officinalis plants", Planta, 210(6), 2000, pp. 925-931.

[39] R. E. Sharp and W. J. Davies, "Root growth and water uptake by maize plants in drying soil.", Journal of Experimental Botany, 36(9), 1985, pp. 1441-1456.

[40] R. J. Stirzaker and J. B. Passioura, "The water relations of the root-soil interface", Plant, Cell \& Environment, 19(2), 1996, pp. 201-208.

[41] H. K. Lichtenthaler and A. R. Wellburn, "Determinations of total carotenoids and chlorophylls a and b of leaf extracts in different solvents", Biochemical Society Transactions, 11, 1983, pp. 591-592.

[42] H. K. Lichtenthaler and C. Buschmann, "Chlorophylls and carotenoids: Measurement and characterization by UV-VIS spectroscopy", Current Protocols in Food Analytical Chemistry, vol. 1, 2001, F4.3.1-F4.3.8.

[43] L. S. Bates, R. P. Waldren and I. D. Teare, "Rapid determination of free proline for water-stress studies", Plant and Soil, 39(1), 1973, pp. 205-207.

[44] A. A. Albalasmeh, A. A. Berhe and T. A. Ghezzehei, "A new method for rapid determination of carbohydrate and total carbon concentrations using UV spectrophotometry", Carbohydrate Polymers, 97(2), 2013, pp. 253-261.

[45] J. J. Irigoyen, D. W. Einerich and M. Sánchez Díaz, "Water stress induced changes in concentrations of proline and total soluble sugars in nodulated alfalfa (Medicago sativa) plants", Physiologia Plantarum, 84(1), 1992, pp. 55-60.

[46] S. Rhizopoulou, M. S. Meletiou-Christou and S. Diamantoglou, "Water relations for sun and shade leaves of four Mediterranean evergreen sclerophylls", Journal of Experimental Botany, 42(5), 1991, pp. 627-635.

[47] M. S. Meletiou-Christou, S. Rhizopoulou and S. Diamantoglou, "Seasonal changes of carbohydrates, lipids and nitrogen content in sun and shade leaves from four Mediterranean evergreen sclerophylls", Environmental and Experimental Botany, 34(2), 1994, pp. 129-140.

[48] S. Rhizopoulou and W. J. Davies, "Influence of soil drying on root development, water relations and leaf growth of Ceratonia siliqua L.", Oecologia, 88(1), 1991, pp. 41-47.

[49] J. B. Passioura," "Roots and drought resistance", Agricultural Water Management, 7, 1983, pp. 265-280.

[50] P. Baltzoi, K. Fotia, D. Kyrkas, K. Nikolaou, A. T. Paraskevopoulou, A. R. Accogli and G. Karras, "Low water-demand plants for landscaping and agricultural cultivations - A Review regarding local species of Epirus/Greece and Apulia/Italy", Agriculture and Agricultural Science Procedia, 4, 2015, pp. 250-260.

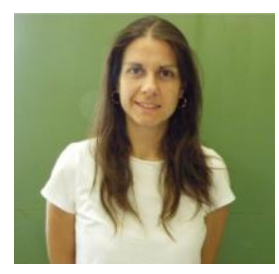

Chrysanthi Chimona has obtained her degree of Biology in the National and Kapodistrian University of Athens. She immediately continued as a $\mathrm{Ph} . \mathrm{D}$. student in the same University, which she obtained with a scholarship co-financed by the European Union (European Social Fund - ESF) and Greek national funds (Research Funding Program: Heracleitus II). Her Ph.D. thesis is entitled 'Biomimetics and Water Status of Plant Tissues'. During her Ph.D. studies she participated in the CAREX Summer School on Life in Extreme Environments, which was attended by 40 selected students. She has three published works in scientific peer reviewed journals and nine participations in scientific conferences. Her scientific work has been focused on plant physiology, flowers, surface structures and their properties, as well water relations and status of plant tissues. She is currently working on a post-Doctorate research about resistant to drought Mediterranean plants of urban landscapes. Her research is funded by State Scholarships Foundation Fellowship of Excellence for Postgraduate Studies in Greece - SIEMENS PROGRAM.

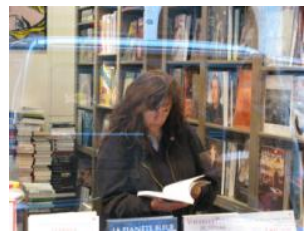

Sophia Rhizopoulou is Professor of Plant Environmental Physiology at the National and Kapodistrian University of Athens in Greece, Faculty of Biology and Department of Botany. Her research interests include plant environmental physiology, plant water relations, adaptations of Mediterranean plants, root development, micro- and nano-sculpture of plants' surfaces, wettability and living archives. Her research has been published in many books and articles. She attended numerous national and international conferences and workshops. She supervised more than a hundred Diploma-, Master- and PhD-Theses; for further details see information presented in http://publicationslist.org/sophia.rhizopoulou. 